\title{
Diario de una infancia. Mariana
}

\section{Diary of a Childhood. \\ Mariana}

\author{
Silvana Casal \\ Universidad Michoacana de San Nicolás de Hidalgo, México \\ (D) orcid.org/0000-0001-6291-042X \\ silvanacasal@gmail.com
}

Resumen: Este artículo está centrado en el análisis del diario de infancia que una de mis entrevistadas, Mariana, escribió durante su niñez en la dictatorial República Argentina a partir del secuestro de su padre, producido en 1977, situación que dio pie al exilio familiar en México. Mariana nos permite entrar en su universo, conocer sus sentimientos y emociones, y acercarnos -mediante sus palabras plasmadas en las cartas que le escribe a su padre desaparecido- a su vida cotidiana $y$, a través de ella, a la de muchos otros niños que vivieron situaciones de violencia similares. Mi propósito es enfatizar que los niños son actores sociales y su aporte es vital en la construcción de una historia que los incluya como agentes activos. Abordaré la importancia histórica de escuchar la voz de los niños y el significado de acceder a escritos elaborados por ellos mismos durante la infancia.

Palabras clave: historia; infancia; violencia; Argentina; México.

Abstract: This article analyzes the childhood diary that one of my interviewees, Mariana, wrote during her childhood in the Argentinian dictatorship after her father was abducted in 1977 and the family was exiled to Mexico. Mariana allows us into her universe and shares her feelings and emotions. Her words, in letters to her missing father, illustrate her everyday life and that of many other children experiencing similar situations of 
violence. My aim is to show that children are social actors, whose contribution is vital to constructing a history that includes them as active agents. I address the historical importance of listening to children's voices, and the significance of their childhood writings.

Key words: history; childhood; violence; Argentina; Mexico.

Fecha de recepción: 19 de julio de 2016 Fecha de aceptación: 12 de octubre de 2016

\section{INTRODUCCIÓN}

E ncontrar la voz de los niños en el pasado es difícil y es uno de los desafíos de los historiadores que se ocupan del campo de la historia de la infancia. Establecer el papel de los niños como actores históricos y destacar su presencia en el pasado es una tarea historiográfica valiosa y necesaria, dado que incluir dichas voces es una forma de reivindicar los derechos de los niños como protagonistas históricos. Pero es importante mencionar que dar voz a los niños no es sólo dejarlos hablar, tal como plantea Allison James (2007, p. 262); se trata de explorar la contribución única a nuestra comprensión y la teorización sobre el mundo social que las perspectivas de los niños pueden proporcionar. James advierte acerca del riesgo de pasar por alto la diversidad de las experiencias, la variedad de los mundos y la propia vida de los niños como individuos. Pero sentencia: "Personalizadas e individualizadas, los niños nos cuentan sus experiencias de la vida cotidiana y revelan las heridas ocultas y las humillaciones de sus experiencias y de cómo muchas veces los adultos las descartan considerándolas como poco importantes." (p. 264).

En primer lugar, en este artículo abordaré de manera breve el contexto histórico de la República Argentina durante los años de la dictadura militar (1976-1983). Posteriormente realizaré una descripción de las fuentes que utilizo para construirlo: los escritos infantiles, principalmente los diarios de infancia, con la finalidad de comprender la importancia de los mismos como fuente histórica; en tercer lugar analizaré las cartas que Mariana le envía a su padre a partir de su desaparición forzada para así acceder a las vivencias que esta niña experimenta en el contexto violento y oscuro que le tocó vivir. Finalmente cerraré el artículo con reflexiones que apuntan a comprender que los niños son actores sociales que ofrecen una perspectiva única acerca de los

\section{()(1) $\$$}


problemas que los involucran y de ciertas vivencias que experimentaron en determinados momentos de su infancia. Escuchar sus voces implica atender tanto lo que en cada contexto sucede como el sentido que tiene para quienes están involucrados.

\section{EL CONTEXTO HISTÓRICO}

En esta investigación he podido acceder, gracias a la generosidad y valentía de Mariana Masera, a una parte de su diario de la infancia: las cartas que le escribió a su padre cuando fue secuestrado y desaparecido por las Fuerzas Armadas de la República Argentina. Este hecho plantea la necesidad de explicar al menos brevemente los sucesos que Argentina atravesó en los años en los que se desarrolla la historia de Mariana con la finalidad de ofrecerle al lector algunas herramientas que lo ayuden a imaginar lo que significó para esta niña vivir las experiencias que detallaré en el apartado cuatro durante los años oscuros en aquel país del cono sur.

La República Argentina ha vivido durante el siglo xx seis golpes de Estado, encabezados por las Fuerzas Armadas. El último de ellos dio inicio el 24 de marzo de 1976. Aquel día comenzó lo que sus protagonistas directos denominaron "El Proceso de Reorganización Nacional" y otros sectores de la población "La Dictadura Militar". La Junta de Comandantes en Jefe, integrada por el general Jorge Rafael Videla (Ejército), el almirante Emilio Eduardo Massera (Marina) y el brigadier Orlando Ramón Agosti (Fuerza Aérea) tomó el poder por medio de la fuerza y nombró presidente de la nación a Jorge Rafael Videla.

Dado que el país había atravesado diversas dictaduras sucedidas por breves periodos democráticos existía cierto sentimiento de aceptación por parte de algunos sectores de la población para convivir con ese clima represivo pero, por otra parte, un sector importante comenzó a expresarse a través de diferentes canales para terminar con la situación política imperante en el país. Muchos trabajadores, por ejemplo, comenzaron a actuar en defensa de sus derechos en sus lugares de trabajo: obreros en sindicatos de fábricas, profesores en los espacios de las universidades, estudiantes en sus centros de estudios, participando en huelgas y manifestaciones. Y por supuesto estuvieron quienes decidieron hacerlo por medio de la lucha armada, persiguiendo un cambio radical del sistema social, político y económico.

El terrorismo de Estado desatado a partir de 1976 y ejecutado por las fuerzas armadas y de seguridad, que se desarrolló con el beneplácito de cier-

\section{(ㅇ)(1) $(3$}


tos sectores de la población, de ciertas instituciones nacionales como la cúpula de la Iglesia católica, partidos políticos conservadores, medios de comunicación, algunas empresas nacionales y extranjeras junto a sus gobiernos, desencadenó una represión sin antecedentes en la historia nacional instaurando los campos de concentración y la desaparición de personas como parte del funcionamiento del sistema político (CONADEP, 1984).

Dado el contexto mencionado, los militares golpistas, una vez instalados en el poder, constituyeron una junta de gobierno que estuvo por encima de la Constitución Nacional, intervinieron el poder judicial y suprimieron el funcionamiento de las cámaras legislativas. Todas las instituciones de gobierno fueron intervenidas y la fuerzas armadas se erigieron como autoridad unívoca que poseía el monopolio de toda decisión política. La actividad de los partidos políticos fue disuelta junto con cualquier actividad sindical. En conclusión, las libertades públicas de los ciudadanos fueron suprimidas, se activó el estado de sitio y se promulgó la pena de muerte para acciones en contra de la patria.

El gran elemento vertebrador del gobierno golpista era la lucha contra la subversión. Las organizaciones armadas, Montoneros y el Ejército Revolucionario del Pueblo (ERP) ya habían perdido presencia dada la cantidad de bajas que habían sufrido en sus filas, pero a inicios del golpe desarrollaron ciertas acciones armadas contra el gobierno. Sistemáticamente el Estado desplegó una política represiva no sólo contra dichas organizaciones, sino contra toda persona que pudiera ser sospechosa de opositora. Esto implicó el aniquilamiento de todo antagonismo y la persecución de cualquier tipo de resistencia. Fue el campo de concentración el eje de un terrorismo de Estado basado en la persecución, el secuestro, la desaparición, la tortura y el asesinato de miles de personas.

Los crímenes cometidos por el Estado argentino fueron justificados dentro del círculo de las autoridades nacionales por la amenaza que representaban los grupos guerrilleros de aquellos años. Esta idea fue la base que permitió constituir la "Teoría de los dos demonios"1 a partir de la llegada de la democracia en 1983 y que pretendió equiparar la violencia estatal con la violencia guerrillera. Dicha teoría dejaba fuera de la ecuación cualquier

${ }^{1}$ La teoría de los dos demonios fue presentada en el informe de la Comisión Nacional sobre la Desaparición de Personas (CONADEP) en el prólogo del Nunca más, nombre que llevó dicho informe. Fue ampliamente discutida dado que tras la doble condena ocultó una justificación del terrorismo de Estado.

\section{()(1) $\$$}


protesta que no fuera armada, como la de los trabajadores que reclamaban sus derechos, arrebatados por el gobierno. Y fundamentalmente no incluía a quienes eran considerados opositores por poseer una opinión crítica sobre el accionar de la junta de gobierno: algunos sacerdotes, abogados relacionados con la defensa de los derechos humanos, intelectuales. Tanto profesores como estudiantes con ideas políticas diferentes a las del gobierno corrían graves riesgos de ser objetivos de los grupos de tareas que ejecutaban las órdenes a través de la cadena de mandos (Romero, 2001, pp. 210-211).

El país se transformó, simbólicamente, en un centro de detención en el que todos sus habitantes estaban controlados, observados y privados de la protección que la Constitución nacional le debía a cada uno de sus ciudadanos.

En conclusión, el gobierno dictatorial inició a partir del golpe una represión sistemática, organizada y planeada por el Estado para combatir lo que los militares dieron en llamar "La subversión apátrida" o "La subversión marxista”. Este plan organizado y racional, respondía a lo que Zygmunt Bauman denominó masacres modernas, es decir, matar con una finalidad. Fueron blanco de la represión miembros de organizaciones armadas como Montoneros y el Ejército Revolucionario del Pueblo (ERP), además de intelectuales, obreros, estudiantes y profesores universitarios, líderes sindicales y todo aquel que tuviera una postura crítica hacia el gobierno; a veces bastaba con ser familiar o simplemente aparecer en la agenda de algún "sospechoso". Los derechos de las personas fueron totalmente anulados y arrebatados.

Comenzó entonces uno de los momentos más difíciles que ha atravesado el país: secuestros, detenciones clandestinas, campos de concentración, torturas, vuelos de la muerte, fusilamientos, cárcel, niños nacidos en cautiverio, robo de bebés. Todo esto organizado como parte de un proyecto de represión social dirigido hacia aquellos que estuvieran en desacuerdo con el gobierno impuesto y lo manifestaran de alguna manera. Como contraparte, las mencionadas organizaciones armadas llevaban adelante diversas operaciones (por ejemplo secuestros de militares o empresarios a cambio de una recompensa en dinero) con la finalidad de armarse y poder enfrentar al gobierno militar. El saldo nefasto de estos años de oscurantismo en la República Argentina fue de 9000 desaparecidos de acuerdo con las cifras oficiales, reclamadas por el Informe de la Comisión Nacional para la Desaparición de Personas (ConAdeP) presentado en 1985. Treinta mil (30 000) es la cifra que las organizaciones de derechos humanos reclaman. Además del miedo y la desconfianza inyectados en la sociedad que duraría varias generaciones. La

\section{()(1) $(9$}


palabra "desaparecidos", que hace alusión a la negación de la identidad de las víctimas, fue reconocida internacionalmente sin necesidad de traducción. Héctor Schmucler (1996) sostiene "Hay un acto que es peor que la muerte y que no encuentra explicación en ninguna contingencia histórica: negar la posibilidad de morir como ser humano, desdibujar la identidad de los cuerpos en los que la muerte puede dejar testimonio de que ese que murió había tenido vida" (p. 9).

El caso en el que se enmarca el secuestro del padre y el abuelo de la niña está relacionado con cuestiones económicas. Ambos eran empresarios, dueños de propiedades, tierras y viñedos, cuyas escrituras debieron ceder en los sótanos de la Escuela de Mecánica de la Armada (Esma), ${ }^{2}$ donde presuntamente estuvieron privados de su libertad y donde se los vio por última vez (CONADEP, 1984). El robo de los bienes de quienes eran desaparecidos fue un hecho lamentablemente común y que posteriormente fue investigado durante la democracia. Esto era acompañado por un aparato de falsificación de documentos que funcionó en los sótanos de la Esma y que permitía realizar este tipo de delitos como la venta de propiedades, ocupación de viviendas que pertenecían a desaparecidos, utilización de vehículos robados, etc. (CoNADEP, 1984). Por el caso que menciono en este artículo, y por tantos otros, la ex jueza federal Emilia Marta García fue procesada por delitos de asociación ilícita y extorsión durante los años de la dictadura (1976-1983), por su presunta actuación en el robo de bienes de desaparecidos durante su secuestro en la EsmA. ${ }^{3}$

A partir de 1976, incluso algunos años antes, comenzó en Argentina, como consecuencia de este contexto histórico, el exilio de miles de personas que escapaban de la persecución y la muerte. Mariana y su familia fueron parte de este proceso. En 1978 se habían establecido en México, sin saber a ciencia cierta dónde estaban y qué había sido de su padre y su abuelo.

${ }^{2}$ La Esma fue la Escuela de Suboficiales de Mecánica de la Armada, una institución oficial, ubicada en la avenida Libertador de la Ciudad Autónoma de Buenos Aires, que tenía la función de formar a suboficiales en aspectos mecánicos y de ingeniería de navegación. Durante los años de la dictadura (1976-1983) funcionó, en los sótanos, como un centro clandestino de detención en donde se torturaba y se definía el futuro de las personas que por allí pasaban. Actualmente funciona como Espacio para la Memoria y para la Promoción y Defensa de los Derechos Humanos.

${ }^{3}$ García fue síndica de la sociedad fantasma Will Ri, que crearon los ex represores Jorge "Tigre" Acosta, Francis William Wahmond y Jorge Rádice para apoderarse de campos ubicados en Chacras de Coria (Mendoza), que eran propiedad de los mendocinos Victorio Ceruti (abuelo de Mariana), Conrado Gómez y Horacio Palma, secuestrados y asesinados en la EsmA. Véase nota completa en http://edant.clarin.com/diario/2007/11/21/elpais/p-00902.htm

\section{()(1) $\$$}




\section{LA IMPORTANCIA DE LOS ESCRITOS INFANTILES}

Muchas de las aproximaciones a las experiencias de la niñez se hacen a partir de los relatos que los adultos hacen de sus propias vivencias de la infancia, transformándose estas en representaciones de dichas vivencias. Esto sucede dado que no es común ni sencillo encontrar escritos que los propios niños del pasado hayan hecho a edades tempranas. Por ejemplo, antes de 1800 sólo hubo siete diarios conocidos escritos por niños en Inglaterra y Estados Unidos y seis en los Países Bajos. Entre ellos se menciona a Otto van Eck, quien entre sus siete y diez años escribió 1500 páginas. El niño elaboró su diario, a instancias de sus padres, de acuerdo con una estrategia educativa recomendada por pedagogos desde finales del siglo XVIII, según la cual la escritura de un diario estaba destinada a aumentar el conocimiento propio del niño. Los padres comenzaron a leer los diarios de sus hijos con el fin de seguir de cerca su desarrollo. En el siglo xix la redacción de los diarios se hizo especialmente popular entre las mujeres jóvenes. El más conocido de este periodo es de origen ruso, de Marie Bashkirtseff, quien comenzó a escribir cuando tenía quince años. Su diario fue publicado por su padre en 1887 a raíz de su muerte prematura. En algunos casos, ciertos diarios de infancia fueron conservados por los padres a causa de una muerte temprana de los niños, como una manera de recordarlos; este fue también el caso de Otto van Eck, quien murió a los 17 años. El diario de Ana Frank, por ejemplo, también se ajusta a este patrón. La primera edición de dicho diario fue publicada en 1947 por iniciativa de su padre. Hacia el siglo xx los diarios infantiles se transformaron en una forma de escritura privada, íntima, en donde los niños volcaban sus vivencias. ${ }^{4}$

Susana Sosenski (2015) acaba de publicar el diario de Conxita Simarro, escrito entre 1938 y 1944 a la edad de once años. Conxita fue una niña que se vio envuelta en el contexto de la guerra civil española que se traslapaba con la segunda guerra mundial. Afectada su familia, de ideología republicana, tuvieron que moverse constantemente: de Barcelona a Francia para posteriormente exiliarse en México. Este es un documento de gran valor dado que la voz de la niña, quien le escribe a "su amigo", nos permite conocer sus intereses, sus sueños, su relación con sus amigos y con su familia, su entrada en la adolescencia, siendo además testigo presencial de acontecimientos marcados por la violencia, la muerte y finalmente el exilio (Sosenski, 2015, pp. 13-30).

\footnotetext{
${ }^{4}$ http://www.faqs.org/childhood/Ar-Bo/Autobiographies.html (noviembre de 2015).
}

\section{()(1) $(9$}


Philippe Lejeune (2005) es un investigador que, apasionado por los escritos de la vida cotidiana, ha dedicado su carrera a trabajar autobiografías y diarios. Plantea que el diario ha existido desde tiempo atrás, como una técnica comercial, de gestión política, de registro y que lo que hoy conocemos como diario íntimo, aquel que hace hincapié en la historia personal, se dio a conocer a partir de los siglos XVII-XVIII. Lejeune (2005) sostiene que hay dos tipos de diarios: los vivos y los muertos. Un diario vivo es aquel al que el autor alimenta con sus escritos todos los días. Un diario muerto es aquel que pertenece a una persona fallecida o a una persona viva pero que ha dejado de escribirlo.

Pero, ¿cómo abordar el análisis de un diario para que sea trabajado como una fuente primaria por el historiador? En primer lugar Lejeune (2005) advierte acerca de ser cuidadosos por los daños que podría causar un texto que proviene de un diario íntimo si este fuese leído por la familia del autor o en su lugar de trabajo, dado que pueden mencionar nombres y situaciones tal vez desagradables o indiscretas. Por otra parte explica que muchas veces los diarios se presentan de manera fragmentada, mal escritos: con faltas de ortografía, redacción confusa, desordenados, pero tienen la virtud de ser una huella auténtica de lo que sentía el protagonista en el momento en que lo escribió; es por esto que recopilando distintas huellas es posible tener un panorama más amplio de la historia de esa etapa de la vida. Lejeune (2005) define al diario como: "Una serie de huellas fechadas" (p. 13).

El diario tiene como primer destinatario a su propio autor. Es escrito para uno mismo, es una producción privada, un manuscrito, una huella.

El diario es mi escritura del instante, el cuaderno que compré, la forma en que escribí, mi escritura nerviosa. Para mí es un objeto único. Un diario es, en cierto modo, un relicario y es irreemplazable [...] Es como una obra de arte, existe uno y las reproducciones que se hagan son como una degradación, un empobrecimiento, aunque esta degradación y este empobrecimiento sean necesarios naturalmente para lograr una mejor comunicación (Lejeune, 2005, p. 13).

Lo valioso del diario de infancia es que permite al lector captar el momento en el que los sentimientos afloran a través de la escritura, es como tomar una fotografía de una circunstancia determinada. Es la voz del niño, genuina, legítima, directa, que representa sus puntos de vista y sus opiniones en ese momento de su vida. Esas palabras que están plasmadas en esos textos

\section{()(1) $(3$}


nos permiten explorar qué sucedió, cómo determinada situación de vida fue vivida y explorar las perspectivas y puntos de vista de los niños como actores sociales, dado que expresan lo que es ser un niño en un entorno social y cultural determinado.

Helena Jackson Albarrán (2012, pp. 20-24) advierte que si bien uno de los riesgos que presentan las fuentes infantiles es la imposibilidad de confiar en su total autenticidad, dado que pudieron estar influenciadas por el mundo adulto que rodea a los niños, no hay que olvidar que todo documento histórico sufre de las mediaciones de otros, antes de llegar a las manos de los historiadores y luego por los mismos historiadores. Y que los niños tienden a ser los más transparentes y menos filtrados en sus reacciones en relación con su ámbito cultural. Sostiene Jackson (2012): "Nuestra tarea es separarlo [al testimonio] de sus capas de influencias ajenas para examinar - en la medida de lo posible- las distintas influencias e intervenciones de los adultos y las convenciones sociales que rigen la producción cultural infantil, siempre con una sensibilidad al contexto histórico y personal que contribuye a su formación" (p. 24).

En cuanto a las mediaciones de los adultos es importante tener en cuenta que en este caso presentaré un diario íntimo, es decir, un documento que es parte de la vida privada de esta niña y que probablemente nadie, ni su madre ni sus hermanos, hayan tenido acceso a él. Si bien los adultos no han participado en la elaboración de estas líneas dado que era un diario personal, es posible considerar que las influencias de los adultos que la rodeaban estén presentes en la formación de sus ideas.

Presentaré parte del diario de infancia que la protagonista me entregó. Son diez escritos que realizó a su padre a partir del momento de su secuestro por parte de las Fuerzas Armadas de la República Argentina.

Es este un documento de gran valor histórico, dado que el testimonio rescata la voz y la perspectiva infantil de ciertos sucesos generadores del exilio que cambiarían su vida personal y familiar.

\section{EL DIARIO DE UNA NIÑA}

La historiadora Elena Jackson Albarrán (2012) plantea que la historia de la niñez siempre está sujeta a la interpretación de los adultos y que lo que se sabe del pasado de los niños proviene principalmente de mediadores como instituciones escolares y de bienestar, o de la familia, o de los maestros. La

\section{(이)( $\$$}


posibilidad de recopilar las experiencias de los niños a través de los relatos de los adultos que fueron esos niños, es de un valor inenarrable, "Sin embargo, no es paralela al poder de un documento que contiene la impresión de una experiencia dejada por un niño en el momento en que la vive” (p. 21).

Acceder a fuentes primarias generadas por los propios niños es una tarea bastante difícil pero, cuando sucede, permite ilustrar su papel como agentes históricos y abre caminos para interpretar y analizar documentos creados por ellos mismos (Jackson Albarrán, 2012, pp. 17-52).

De acuerdo con el planteo de Lejeune (2005), el diario íntimo, que constituye una fuente primaria producida por el propio sujeto histórico, es un objeto único, irremplazable y de un valor fundamental para plasmar el punto de vista del creador de dicha fuente.

El diario, que mi entrevistada me confía, contiene diez textos diferentes escritos en la República Argentina cuando la niña tenía entre once y doce años, antes de partir hacia el exilio mexicano. Comienza en 1977, con la desaparición de su padre, a describir cómo ella percibía lo que estaba sucediendo en el país y que luego sería el motivo que los impulsaría al exilio. Este diario condensa experiencias del año que vivió en Argentina a partir del secuestro y la desaparición de su padre y su abuelo y expresa cómo esas situaciones vividas dieron forma a parte de las actividades que la niña llevaría adelante posteriormente en su vida adulta.

La primera carta comienza con la expresión "Hablo con papi". Es significativo que use el verbo hablar en lugar del verbo escribir; en este sentido, la carta pretende ser desde el principio un medio de comunicación en tiempo real con su padre, aun sabiendo que no la va a leer, al menos inmediatamente. Continúa: "Cada día que pasa te quiero muchísimo más, cuando pienso en vos me dan ganas de ir a buscarte, agarrarte e irnos lejos para olvidar esta pesadilla. Pido a Dios que sea corta, muy corta para que mami y vos sean felices. Yo ofrezco los 6 años de estudios y dejar a todas mis amigas."

Dos elementos se pueden vislumbrar a partir de estos escritos breves. En primer lugar la niña expresa el dolor y la angustia que la ausencia del padre genera para ella y para su madre, que no puede ser feliz sin su presencia. Expresa cierta confusión y turbación dado que no conoce con certeza cuándo terminará esa etapa de ausencia. Por otro lado manifiesta esperanza de que su padre volverá y sus creencias católicas son muy fuertes, no sólo porque menciona a Dios sino porque tiene incorporada la idea de sacrificio: ofrece su entrega al estudio y renuncia a sus amigas para que su padre regrese a la vida familiar.

\section{()(1) $(3$}


Continúa: "Ya pasó un mes. Se acerca mi cumpleaños. Cumplo doce años en tres días. Espero que esta pesadilla pase pronto. Esto ha sido para mí lo peor, el terremoto o el fin, pero ya tengo el triunfo en la mano: Dios haz salir a papi, toda mi vida a cambio de él."

Le dice a su padre cuándo cumple años y cuántos cumple, como si quisiera dejar testimonio de los años que tiene, para un futuro lector del diario o para sí misma, para recordar tal vez, el momento en que escribió estas palabras. Comienza a narrar las primeras emociones, expresa lo que para ella significó esta situación de desconsuelo, las palabras que utiliza para describir lo que está viviendo y sintiendo son pesadilla, lo peor, terremoto, el fin. Es esta la perspectiva de una niña abatida por un contexto político y social que la golpea, y lo expresa en voz alta y con valentía en sus escritos. Son estos una evidencia genuina y válida de sus vivencias. Y nuevamente el sacrificio: dar su vida a cambio de la de su padre.

Por Papi. Papi aguanta, ten fe, no decaigas, todos estamos bien, todos te haremos salir pronto. Sé un palo, no escuches a ninguno de ellos, es mentira. Papi falta poco para llegar a ese día que nos volverá a juntar. Tené fe en Dios, por favor. No decaigas, aquí estoy yo para darle esperanzas a mami y fuerzas [...] Todos deseamos estar junto a vos, para que eso suceda necesitamos que tengas fe.

Se despide con un "Chau papi" y escribe su nombre. Esta carta ya no la escribe para papi sino por papi, es decir, es su manera de contribuir al rescate de su padre. Aquí comienza la etapa en la que se construye a sí misma como soporte de su padre y de su madre. Asume un papel de sostén de los que están y de los que no están. Incluye a la familia entera en la lucha por encontrarlo y se constituye como vocera del grupo familiar. Aconseja y comienza a entender que existe un mundo de mentiras y mezquindades del que quiere proteger a su padre. Y siempre la idea constante de la existencia divina que va a interceder y a ayudar. "Ahora comprendo por qué no hay que jugarse por los amigos ¿por qué te preguntarás? Porque son unos cobardes todos. En este mundo nadie se juega por los demás [...] Este mundo, querés que te diga papi, no lo comprendo. No comprendo a los adultos, ¿por qué se matan? ¿por qué papi?"

Comienza aquí una etapa de decepción y de confrontación con la realidad y el mundo de los adultos. Su razonamiento se observa más maduro y le permite advertir que lo que está viviendo su familia es parte de un todo, de

\section{()(1) $(3$}


una problemática general del país. Este escrito refleja una característica de la sociedad argentina de aquellos años que fue la aceptación por parte de ciertos sectores de la población del discurso oficial, de que si las cosas sucedían era por un motivo. Gran parte de la sociedad fue aceptando poco a poco ese discurso oficial y se sumó a las frases que se acuñaron en la época, impulsadas por los medios de comunicación que adherían al gobierno, y por el mismo gobierno: "por algo será" y/o "en algo andaría", frases que eran aplicadas a las personas que eran desaparecidas en aquellos años como una especie de explicación de que nadie desaparece porque sí, sin razones. La sociedad utilizaba esta expresión también como una manera de sosegar el temor a ser desaparecido si no había un motivo fundado para que esto sucediera.

Se produjo, por otra parte, cierta internalización de la acción estatal que se tradujo en el propio control, la autocensura y la vigilancia del vecino (Romero, 2001, p. 211). Sebastián Carassai (2009) plantea que no existía, en la década de los setenta, conciencia social acerca de los derechos humanos, es decir, la idea de la existencia de derechos invulnerables para todas las personas, independientemente de su clase social o ideología política, estuvo ausente del debate público nacional y de las preocupaciones de la sociedad civil. Es más, las personas no apelaban a sus derechos como ciudadanos, sino que estaban sumergidas en ese clima de temor que habitaba en la sociedad argentina. Incluso las tres primeras organizaciones surgidas a partir de la dictadura, como fueron Familiares de Desaparecidos y Detenidos por Razones Políticas, Madres y Abuelas de Plaza de Mayo, no se consideraron en un inicio como agrupaciones de derechos humanos, esa idea surgió posteriormente.

En el entorno familiar de la niña, entre sus tíos, sus abuelos y los amigos cercanos, había comenzado una cierta dinámica de marginar a la familia de la pequeña, a su madre y a sus hermanos, cargándolos con la culpa de la desaparición de su padre. ${ }^{5}$ Esto explicaba también el clima de confusión que se vivía en la sociedad. Pero lo que la niña percibe es la traición, la deslealtad de quienes en tiempos previos habían sido muy cercanos y ahora los abandonaban. Esto se relaciona con que existía un temor social de correr riesgos si se era amigo de alguna persona que hubiera sido secuestrada. La cobardía a la que hace referencia la niña en el párrafo anterior implica marcar su pos-

${ }^{5}$ El hermano de la madre de la niña militaba en la agrupación Montoneros, y ciertos familiares, como los abuelos paternos y otros amigos, culpaban a la mamá porque consideraban que cuando los militares atracaron la casa era porque estaban buscando a su hermano, y como no lo encontraron, o en medio de la confusión, se llevaron a su marido.

\section{()(1) $\$$}


tura para defender a su padre de las posibles habladurías de aquellos años: "andaba en algo raro", y también para anular y no aceptar las versiones que comenzaban a esbozarse en la sociedad: que los desaparecidos podrían estar muertos. Por otro lado, aparece en la carta la primera referencia hacia la idea de la muerte. Cuando la niña se pregunta ¿por qué se matan los adultos?, está comenzando a comprender que ese era el clima político de la época y que su propio padre era víctima de esa compleja situación. Tal vez estuviera comenzando a aceptar la posibilidad de la muerte de su padre.

Inmediatamente continúa: "Papi ¿dónde estás? ¿Estarás bien? ¿Esos $\mathrm{H}$ de P te habrán golpeado mucho?" Esta pregunta que se hace acerca del lugar y del estado en el que estaría su padre es un testimonio de que la niña sabía que los militares golpeaban y torturaban. Aquella pregunta encuentra además una nefasta respuesta en una conferencia de prensa que el ex presidente de facto, Jorge Rafael Videla, diera en el año 1979 cuando le preguntaban acerca de los desaparecidos.

Respondió:

El desaparecido, en tanto esté como tal, es una incógnita. Si el hombre apareciera tendría un tratamiento " $x$ ", si la aparición se convirtiera en certeza de su fallecimiento tiene un tratamiento " $z$ ", pero mientras sea desaparecido no puede tener un tratamiento especial: es una incógnita, es un desaparecido, no tiene entidad, no está ni muerto ni vivo, está desaparecido. Frente a eso no podemos hacer nada (Kriegsmarine1942, 2010).

La angustia de no saber si su padre estaba vivo o muerto, de las condiciones físicas en las que se encontraba, del lugar en el que se alojaba, es un sentimiento que se refleja en las palabras de Mariana. Su voz escrita habla por ella pero también puede hacerlo en nombre de muchos otros niños, podría describir otras vidas similares en otras partes del país, incluso en otros contextos históricos. ${ }^{6}$ James (2007) plantea al respecto que es importante

${ }^{6}$ Muchos autores abordaron la temática niños-violencia-exilio en países del cono sur, dado que fue allí que en la década de los setenta se instalaron dictaduras que dieron lugar a persecuciones, secuestros, ejecuciones que involucraron a la población en su conjunto. Nora Rabotnikof (2007, p. 49), menciona a los llamados argen-mex, aquellos niños que nacieron en Argentina antes del golpe y llegaron a México muy pequeños o que nacieron en México y sus padres eran exiliados. Ana Buquet (2008, pp. 125-137) cuenta su experiencia de haber vivido el Uruguay violento siendo una niña, con el recuerdo de su casa bombardeada, de su madre y de su padre detenidos, de tener que vivir separada de sus hermanos, en casas de familiares, mientras sus padres viajaban a Buenos Aires en busca de protección, de donde pronto

\section{()(1) $(3$}


"Reconocer que las diversidades que distinguen a un niño de otro son tan importantes y tan significativas como los puntos en común que podrían compartir" (p. 266).

Tres ideas se prolongan a lo largo de los escritos: la fuerza católica de la niña y la necesidad de que la familia vuelva a estar unida: ella con su padre, con su madre y sus hermanos: "espero que mis rezos te den fuerza para aguantar todo y así podamos estar todos juntos". En la carta remarca y encierra en un círculo la expresión "todos juntos" como un testimonio de que la unidad familiar estaba rota porque su padre estaba ausente y como un modo de crear un espacio cerrado en el que, por lo menos en sus escritos, no los pudieran separar; y la tercera idea que destacan estas cartas es el amor que siente por su padre: "Te quiero tanto que ya no tengo palabras para decírtelo" e inmediatamente un poema: "Padre es el sol de cada mañana, es la aurora de cada día, es el aire, es una flor, una esperanza, una alegría, una tristeza. Padre es todo aquello que se pueda amar." Esto no sólo expresa el sentimiento de apego y afecto hacia el padre, y podría permitirme ensayar la idea de una relación familiar armoniosa (tomando como referencia para esto también el testimonio que de adultos Mariana y su hermano Omar ofrecieron) teniendo en cuenta la siguiente expresión: "Papi te quiero, te extraño, vos, mami y los chicos son todo, todo, todo, todo, todo, todo, todo, todo, todo". Expresiones espontáneas como esta abundan en el diario. Además, los escritos permiten observar el nivel cultural de la niña: escribe, a sus once años, sin faltas de ortografía, con una sintaxis impecable y además logra expresar metafóricamente su sentir. En otro párrafo le cuenta a su padre que su madre compró un poster con el poema "Todavía" de Mario Benedetti, a quien define como un excelente escritor.

tuvieron que huir nuevamente dado el golpe militar de marzo de 1976. El excelente artículo de Pablo Piccato (2008) define la experiencia del exilio infantil desde otro lugar: "El exilio es muchas veces, y quizá con mayor vigor, una secuencia de silencios. Silencio porque todavía duele, silencio por no lastimar a otro, o a veces hasta el silencio por incomprensión" (p. 149). También Carla Antonella Cossi (2012) rescata las memorias de un grupo de niños paraguayos que fueron expulsados junto con sus padres de Paraguay a partir del golpe de Estado de Alfredo Stroessner, que inició en 1954 y se prolongó hasta 1989. Silvia Dutrénit Bielous (2013) analiza, a partir de la subjetividad de los relatos de dos entrevistadas (Natalia Bruschtein y Valentina Ramírez), cómo han procesado y resignificado los sucesos vividos en su infancia, enmarcados en el exilio desde Argentina y Chile, respectivamente, y trabaja sobre las marcas que estos sucesos exiliares han dejado en sus vidas.

7 "No lo creo todavía / estás llegando a mi lado / y la noche es un puñado / de estrellas y de alegría / palpo gusto escucho y veo tu rostro tu paso largo / tus manos y sin embargo / todavía no lo creo / tu regreso tiene tanto / que ver contigo y conmigo / que por cábala lo digo

\section{()ㅜ(1) 3}


A partir del próximo escrito comienza a fechar directamente su diario: 3-VI-77. 142 días. 4-VI-77-143 días, 21.30 hrs. 6-VII-77-146 días, 22.10 hrs. Es decir no utiliza referencias indirectas como la fecha de su cumpleaños, sino día, mes, año y hora. Tal vez contar el tiempo implique para la niña la esperanza de que falta menos para encontrar a su padre o que el tiempo pasa y su padre no aparece.

En el siguiente escrito plantea: "3-VI-77. 142 días. [...] Ahora que no estás le tengo miedo a la noche pues no está esa mano fuerte para defendernos [...] Aunque no llore por fuera lloro por dentro, por tu ausencia [...] Mami necesita de vos, de mí, le trato de dar alegría pero a mí me falta fuerza, porque ¿de dónde saco mi alegría?"

Comienzan a aflorar los miedos, la noche representa ese espacio en el que las cosas terribles sucedieron: aquella madrugada de 1977, en Mendoza, una provincia de la República Argentina, se llevaba a cabo un operativo militar por parte del gobierno inconstitucional. Este tipo de operativos eran comunes en aquellos años y eran ordenados por el gobierno y ejecutados por los denominados grupos de tareas, que impunemente ingresaban en las viviendas por la madrugada con la finalidad de descubrir y atrapar a los potenciales subversivos, guerrilleros o personas emparentadas con ellos. Eran épocas difíciles para vivir en un país en el que la libertad no se permitía en ninguna de sus formas: no había libertad de opinión, de expresión, política, ideológica. En la madrugada del 12 de enero de 1977, la niña de once años a la que pertenece el diario que estoy analizando se despertó en su cama, abruptamente, con una arma en su cabeza. No entendía lo que estaba sucediendo pero pronto lo iría descubriendo: hombres encapuchados entraron en su casa violentamente, golpearon a sus hermanos y a su madre y se llevaron, en medio de la noche, a su padre hacia un destino incierto. La abrupta llegada en la madrugada de un grupo de extraños, los gritos, los golpes, el maltrato, el robo y el peor desencadenante: el secuestro del padre. En la entrevista que sostuvimos, la niña ahora adulta me contaba que durante muchas noches no durmió porque tenía miedo de que volvieran los militares como aquella noche, que esperaba a que amaneciera para poder descansar.

\footnotetext{
/ y por las dudas lo canto / nadie nunca te reemplaza / y las cosas más triviales / se vuelven fundamentales / porque estás llegando a casa / sin embargo todavía / dudo de esta buena suerte / porque el cielo de tenerte / me parece fantasía / pero venís y es seguro / y venís con tu mirada / y por eso tu llegada / hace mágico el futuro / y aunque no siempre he entendido / mis culpas y mis fracasos / en cambio sé que en tus brazos / el mundo tiene sentido / y si beso la osadía / y el misterio de tus labios / no habrá dudas ni resabios / te querré más todavía."
}

\section{()(1) $(9$}


Nuevamente, "4-VI-77-143 días. Mañana es el cumpleaños de mami, ¡cómo te extraña! Yo creo que mami sufre todo lo que te hacen a vos papi." Esta idea de que su padre está sufriendo se reitera en distintos momentos. "Espero que no te hayan golpeado mucho", dice en otra parte. Por aquellos días el secuestro clandestino de una persona implicaba el posterior uso de la tortura para sacar información o simplemente como una manera de disciplinamiento, dado que no estaba permitido oponerse al gobierno de Reorganización Nacional. Diversos fueron los métodos de tortura empleados: la picana eléctrica fue uno de los más practicados, consistía en pasarle electricidad al cuerpo de una persona, previamente atado a una mesa (la mesa de torturas), desnudo y mojado. El aparato eléctrico se aplicaba a las partes más sensibles del cuerpo como las encías y los genitales. También se practicaba el submarino, que consistía en sumergir la cabeza en agua y esperar hasta el punto de la asfixia para sacarlo y las más comunes eran las violaciones sexuales. Esto sumado a otras formas que combinaban la tecnología con el sadismo, puestos al servicio de una operación institucional en la que participaban jefes de alta responsabilidad. A esta tortura física se sumaba la psicológica que consistía en hacer sufrir a los secuestrados un simulacro de fusilamiento, asistir a la tortura de amigos o familiares, entre otras. Si bien la finalidad de estos procedimientos era quebrar al detenido, no se perseguía la muerte, por eso las sesiones de tortura estaban controladas por un médico con el fin de evitarla. La muerte, en todo caso, venía después, cuando la cúpula militar decidía cuidadosamente cuál sería la suerte que correría la vida de esa persona. A pesar de que la junta de gobierno decretó la pena de muerte esta nunca fue puesta en práctica y todas las ejecuciones fueron clandestinas (Romero, 2001, pp. 209-210). ${ }^{8}$ Luego de la sesión de tortura el secuestrado volvía a su celda, en donde muchas veces recibía golpes y maltratos de los cuidadores. Esas celdas carecían de cualquier tipo de higiene, tanto del espacio como de los prisioneros, eran celdas comunes donde las personas estaban desnudas, con un trapo que tapaba sus ojos, sus brazos atados en la parte posterior de su cuerpo, mal alimentadas y sin atención médica ni servicios sanitarios. Y allí esperaban hasta la siguiente sesión de tortura (Romero, 2001, pp. 208-209). Cuando la niña se refiere a los golpes y a lo que sufre su padre puede estar

8 A veces los cadáveres aparecían en las calles como muertos en enfrentamientos o intentos de fuga. En ocasiones se dinamitaron pilas enteras de cuerpos. Pero en la mayoría de los casos los muertos eran enterrados en fosas comunes como personas desconocidas, quemados en fosas colectivas o arrojados al mar con bloques de cemento en sus pies, previamente adormecidos con una inyección de pentotal (Romero, 2001, pp. 209-210).

\section{()(1) $\$$}


haciendo alusión a estas prácticas, que poco a poco empezaban a salir a la luz en la sociedad. Esto permite observar la comprensión de algunos niños sobre los procesos políticos que atravesaba el país en el que vivían y que los involucraban. Con esa pregunta que se hizo dio pistas acerca de su conocimiento sobre un accionar ilegal por parte de los representantes del gobierno del país, es decir, sabía no sólo que su padre había sido secuestrado, privado de su libertad, ocultado en algún lugar, sino también que estaba siendo maltratado; lo que no sabía era dónde y buscaba a través de su propia escritura descubrir el porqué. La niña deja ver su cuestionamiento sobre el accionar del gobierno de aquel país que llevaba adelante actos de barbarie como el que le tocó vivir y que afectó sustancialmente su vida. Condena al gobierno que secuestra gente y la mantiene encerrada de manera clandestina, sin dar explicaciones ni datos de dónde están esas personas y de por qué han sido secuestradas.

También percibe cómo los medios de comunicación estaban censurados, cooptados, intervenidos: "Estamos en el tren, mami lee las noticias en la revista La Opinión enterándose un poco de lo que sucede. No lee mucho, pues lo que dicen mami ya lo sabe." El gobierno militar se ocupó de controlar todo tipo de producción cultural, por lo que los medios de comunicación, tanto privados como públicos, se encontraban acorralados y muchos ${ }^{9}$ apoyaron y justificaron desde sus editoriales las políticas del gobierno, ocultando o tergiversando la información de acuerdo con lo que el gobierno requiriera. Pero el diario La Opinión, al que Mariana hace referencia, fue fundado en 1971 y dirigido por Jacobo Timmerman hasta 1977, año en que fue detenido por los militares. El periódico surgió con la idea de expresar una crítica al autoritarismo y a la violencia del momento pero con la detención de su director fue intervenido por los militares y entró en un periodo de decadencia hasta 1980 en que dejó de aparecer. Ser periodista crítico en tiempos de la dictadura fue una profesión muy peligrosa y es muy larga la lista de desaparecidos que se desempeñaban en este campo (Varela, s. f.).

En un extracto muy interesante de uno de los escritos menciona: "Yo por mi parte he decidido dejar todo para volver a empezar en otro país." Este es un elemento muy fuerte dado que es un testimonio claro de que la idea de exiliarse ya estaba presente en la familia. Ella hace de esa decisión algo

${ }^{9}$ La Revista Humor fue uno de los pocos ejemplos de periodismo argentino que tuvo una actitud crítica frente al gobierno de facto, aprovechando el humor para hablar de temas que estaban proscritos por la política cultural del gobierno de facto. https://sites.google.com/site/ 301comunicacion/home/el-derecho-a-la-informacion/censura-y-dictadura-militar [Consulta: febrero de 2015]. También el periódico Buenos Aires Herald publicaba listas de desaparecidos.

\section{()(1) $\$$}


propio, juega a ser un adulto, como si su maduración hubiese sido forzada y abrupta. Pero por otra parte deja observar que apoyaba la decisión familiar, en este caso de su madre, de dejar el país a pesar de lo que implicaba. Era aceptar la idea de que se irían sin su padre, que dejarían la casa, sus perros, sus juguetes, su escuela, su entorno.

A partir de los siguientes escritos comienza una etapa diferente dentro de los sucesos que se generaron a partir del secuestro del padre. Comienza la búsqueda activa que lleva adelante la madre acompañada por la niña.

6-VII-77-146 días. Pasan los días y no logramos encontrarte [...] Hoy vamos a Buenos Aires dispuestos a encontrarte pues tenemos la noticia de que estás en las listas y esta vez más vale que nos lo digan [...] estoy muy ilusionada con este viaje [...] Mami va con esperanza y yo también. [...] Hoy caminamos con mami más de 40 cuadras para ir a ver a monseñor X [no se entiende el nombre] al edificio de la armada. Esperamos 3 horas a que nos atendiera.

Este papel que asume la niña de once años en la búsqueda de su padre, confirma la idea inicial de los niños como actores históricos y sociales que protagonizan los sucesos que los involucran, niños que son parte de la historia. La niña le decía a su padre: "Hoy vamos a Buenos Aires dispuestas a encontrarte [...] Te vamos a sacar", asumiendo una actitud activa en ese proceso de búsqueda del que ella fue parte. La niña menciona en su diario que creen que su padre está "en las listas", esto es posible relacionarlo con dos cuestiones. Por un lado, con el hecho de que un secuestrado era llevado a un centro de detención para su interrogación. Estas detenciones eran ilegales y el gobierno no reconocía la existencia de esta infraestructura montada para concentrar a los opositores o sospechosos. Muchas de las personas que fueron secuestradas posteriormente a los interrogatorios realizados en los campos eran transferidas al Poder Ejecutivo Nacional, es decir, se transformaban en detenido legales, reconocidos por las autoridades y encerrados desde ese momento en la cárcel. Por otra parte, ciertos miembros de la alta jerarquía de la Iglesia, conectados con las autoridades militares, poseían ciertas listas de personas que habían sido secuestradas y estaban desaparecidas. Allí se asentaba la situación de la víctima, figuraba si estaba con vida o muerta. Diversos testimonios del Nunca Más documentan acerca de dichas listas:

A los 40 días de la desaparición fuimos a ver a Monseñor Grasselli quien nos dijo que volviésemos a los 8 días. Transcurrido ese lapso volvimos a verlo y

\section{()(1) $(3$}


Grasselli nos mostró una lista con muchos nombres, nos dijo que nos fijásemos en el nombre de nuestro hijo, aquellos que tenían una cruz quería decir que estaban muertos, si no, que estaban vivos. Según esto, la víctima estaba con vida [...] (CONADEP, 1984). ${ }^{10}$

Para la niña la lucha de su madre fue también su lucha y la esperanza fue parte de esta triste experiencia: "Ayer fuimos al edificio de la Armada y hoy la llamaron por teléfono y le dijeron que fuera a las 9 hrs. Creemos que nos dirán dónde estás. Qué nervios, qué impaciencia, qué alegría.” Es importante tener en cuenta que las primeras informaciones acerca del destino y de la suerte corrida por las personas secuestradas provenían del exterior, personas que se habían exiliado contaban lo que sucedía en lugares como la Escuela de Mecánica de la Armada, por ejemplo. La prensa internacional y algunas personalidades del mundo cultural y político extranjero fueron determinantes para arrojar un poco de claridad a tanta confusión (Carassai, 2009, p. 343).

En todo momento Mariana se incluyó en las actividades de búsqueda y manifestó su entusiasmo ante el posible desenlace del encuentro. Este tipo de peregrinajes, como los que Mariana y su madre emprendieron, fueron llevados a cabo por muchas personas en situaciones semejantes: la desaparición de algún familiar y la ausencia de información oficial que permitiera conocer qué había sucedido con sus allegados. De hecho la formación de la agrupación Madres de Plaza de Mayo tuvo el mismo inicio: un grupo de mujeres que se encontraban cotidianamente en las mismas entidades: iglesias, hospitales, tribunales, juzgados de menores, dependencias policiales y militares, autoridades municipales, provinciales y nacionales, buscando respuestas acerca de dónde estaban sus desaparecidos. Desde el año 1977 estas mujeres decidieron ponerse un pañuelo blanco en la cabeza para reconocerse y encontrarse en la Pirámide de Mayo, ${ }^{11}$ frente a la Casa de Gobierno para reclamar noticias sobre sus hijos. Dado que en el país estaba vigente el estado de sitio (que prohibía, entre otras cosas, las reuniones públicas) las personas no podían estar detenidas en un lugar determinado por lo que comenzaron a circular alrededor de la Pirámide de Mayo dando inicio a las conocidas rondas de los jueves y formalizando su constitución en abril de 1977 (Carassai, 2009, p. 339).

${ }^{10}$ Denuncia de Adelina Burgos de Di Spalatro, legajo núm. 1526.

${ }^{11}$ La Pirámide de Mayo es una escultura de 19 metros de altura ubicada frente a la Casa de Gobierno (sede del poder ejecutivo nacional) y construida en 1811, para el primer aniversario de la Revolución de Mayo de 1810. La escultura de la pirámide representa a la libertad.

\section{()ㅜ(1) $(3$}


"149 días de la tragedia. [...] 150 días [...] 151 días.” Estas maneras de expresarse por escrito implican, por un lado, como lo mencioné anteriormente, medir el tiempo de la ausencia y, por otro, marcar lo presente que estaba día tras día la situación del alejamiento forzado de su padre quien representaba para ella un recuerdo amoroso, cariñoso, presente aún en la ausencia. En estos escritos le cuenta a su padre cómo pasaron de la esperanza a la desesperanza cuando las promesas de datos para encontrarlo se desvanecían. "Creíamos que te íbamos a encontrar." También comienza a incluir a partir de aquí actividades cotidianas, es decir, menciona en medio del diario que va a "ver a Gaby", o que "fuimos de Matilde" o "después del mediodía vinieron Fabiana, Fuki o Marijo y jugué mucho". Es decir, deja evidencia del proceso de continuar la vida cotidiana en medio de la ausencia, del dolor, de la búsqueda: "Y luego para calmar la desesperación caminamos por Florida y me compré un pullover."

Lejeune (2005) sostiene que escribir un diario "es una manera de vivir con la escritura, de ordenar la vida con la escritura y una técnica de vida. [...] Lo que define al diario es la relación entre lo que se vive y lo que se escribe" (p. 13). En el caso del diario que analizo, la niña vuelca allí todos sus temores, sus fantasías, su dolor profundo, el amor hacia su padre y el apoyo a su familia, como una manera de comprender y de ordenar lo que estaba sucediendo en su vida y que era, en ese momento, muy difícil de aceptar y de entender. Como plantea Lejeune (2005), la niña escribía para ella misma, tal vez para tranquilizarse, para encontrar calma ante tanto desconcierto y para leerlo en otro momento, tal vez con su padre cuando volviera de ese lugar en el que se encontraba pero que nadie conocía. Dice en un extracto "te estoy escribiendo, pues desahogo lo que te extraño".

\section{REFLEXIONES FINALES}

A través de la lectura y análisis de este diario ha sido posible reconstruir parcialmente los sentimientos despertados en una niña por los actos de barbarie que el Estado argentino con su accionar ilegal generó en su vida y en la de su familia, víctimas todos de un gobierno dictatorial que ha teñido de vergüenza a toda la sociedad argentina, cómplice incluso en la ignorancia. A partir del secuestro de su padre comenzó para esta familia una vida nueva, despojada de la cotidianidad familiar y marcada por la ausencia y la desesperación

\section{()(1) $\$$}


sumada a la impotencia de no saber por qué habían sucedido los hechos de aquel 12 de enero.

Dentro de esta familia de, originalmente, cinco miembros, la menor de los hermanos comenzó a expresarse a través de la palabra escrita y nos permitió asomarnos a sus percepciones. La niña padeció maltrato por parte de los intrusos que ingresaron en su casa, observó el maltrato físico proferido a sus dos hermanos y a su madre, escuchó los gritos, los golpes, observó el robo de todo lo que encontraban a su paso; pero todo esto quedó opacado frente a la sustracción violenta de su padre, en plena madrugada, con una capucha en la cabeza.

A partir de estas fuentes fue posible analizar cómo fue procesando la niña esa situación extrema, observar su tristeza, su enojo, su decepción, su desencanto, su ansiedad y su miedo ante lo que comenzaban a atravesar ella y su familia. Y cómo, en medio de semejante situación fue encontrando momentos de alegría y de esperanza ante tanto desasosiego. Mariana creció junto a su diario y estableció una nueva relación con su padre a través de él, le contaba cosas de la vida cotidiana: quién los visitaba, dónde comían, el libro que compraron, las caminatas que hicieron, lo mucho que lo extrañaban, lo orgullosa que estaba de él.

Claramente este tipo de escritos de aquellos que han sido golpeados por ciertos sucesos de la vida sirven como un desahogo, también como una manera de superar la infelicidad de ese momento. Son textos catárticos que permiten expresar la impotencia que experimentan sus autores.

Acceder a la vida cotidiana, en donde la pequeña dijo presente y se hizo visible a través de sus palabras y rescatar su voz nos da la posibilidad de escuchar otras voces. Y comprender cómo algunos niños participaron, a su manera, de los sucesos políticos en los que habían quedado entrampados y cómo se involucraron y fueron protagonistas.

Textos como este diario de la infancia aportan la perspectiva de un sector poco escuchado, que tiene mucho que decir y que al mismo tiempo ha ido ganándose un espacio propio como sujeto real, que se desenvuelve en un ámbito familiar, cultural y que desempeña un papel específico como actor social. La niña habla de sí misma como personaje central de su historia, se enfrenta y se sobrepone a situaciones difíciles de manera activa a pesar de su corta edad. Su testimonio se centra en el impacto que tuvo la dictadura militar argentina en su vida personal y familiar. Y muestra cómo ha luchado para sobreponerse al dolor por la ausencia de su padre, por la desmembración de su familia, por la tristeza de su madre y por tener que dejar la tierra en que nació.

\section{()(1) $(9$}




\section{LISTA DE REFERENCIAS}

Buquet, A. (2008). ¿Hija del exilio o exiliada? En S. Dutrénit Bielous y F. Serrano Migallón (coords.). El exilio uruguayo en México (pp. 125-137). México: Porrúa.

Carassai, S. (julio-diciembre de 2009). Antes de que anochezca: derechos humanos y clases medias en la Argentina antes y en los inicios del golpe de Estado de 1976. Prisma Jurídico, 8(2), 337-362. Universidade Nove de Julho Brasil.

Comisión Nacional sobre la Desaparición de Personas (ConAdeP) (1984). Nunca Más. Argentina: Eudeba.

Cossi, C. A. (2012). La infancia desde lejos: memorias contrapuestas de niños en el exilio. En Jornadas de Trabajo. Exilios Políticos del Cono Sur en el Siglo xx. La Plata 26, 27 y 28 de septiembre. Recuperado de http://jornadasexilios.fahce.unlp. edu.ar/i-jornadas/ponencias/COSSI.pdf/view

Dutrénit Bielous, S. (julio-diciembre de 2013). La marca del exilio y la represión en la segunda generación. Historia y Grafía, año 21(41), 205-241. Recuperado de http:// www.revistahistoriaygrafia.com.mx/index.php/HyG/article/viewFile/60/pdf_46

Dutrénit Bielous, S. y Serrano Migallón, F. (coords.). (2008). El exilio uruguayo en México. México: Porrúa.

Jackson Albarrán, E. (2012). En busca de la voz de los herederos de la revolución. Un análisis de los documentos producidos por los niños, 1921-1940. Relaciones. Estudios de Historia y Sociedad, 33(132), 17-52. Recuperado de http://www.scielo.org.mx/ scielo.php?script=sci_arttext\&pid=S0185-39292012000400002

James, A. (2007). Giving voice to children's voices: practices and problems, pitfalls and potentials. American Anthropologist, 109(2), 261-272. Dor:10.1525/aa.2007.109.2.261

Kriegsmarine1942 (6 de marzo de 2010). Videla habla sobre los supuestos "desaparecidos", 1979. [Archivo de video]. Recuperado de https://www.youtube.com/ watch?v=9MPZKG4Prog

Lejeune, P. (2005). Un journal à soi: historia de una práctica. Intramuros Francia, 22, 12-13.

Piccato, P. (2008). Exilios de segunda generación o desencuentros de primera generación. En S. Dutrénit Bielous y Serrano Migallón, F. (coords.). El exilio uruguayo en México. México: Porrúa.

Rabotnikof, N. (2007). Memorias, exilios y reconocimientos. En F. Serrano Migallón (coord.), El exilio argentino en México a treinta años del golpe militar. México: Editorial Porrúa.

Romero, J. L. (2001). Breve historia contemporánea de la Argentina. Argentina: FCE.

Schmucler, H. (septiembre de 1996). Ni siquiera un rostro donde la muerte hubiera podido estampar su sello. Pensamiento de los Confines, 3. Buenos Aires: FCE.

\section{()(1) $\$$}


Sosenski, S. (2015). Diario de una niña en tiempos de guerra y exilio. 1938-1944. México: Instituto de Investigaciones Históricas-UnAm/Universidad Nacional de Educación a Distancia/Centro de Estudios de Migraciones y Exilios.

Varela, M. (s. f.). Los medios de comunicación durante la dictadura: entre la banalidad y la censura. Recuperado de http://www.camouflagecomics.com/pdf/ 02_varela_es.pdf

\section{OTRAS FUENTES}

Diario de infancia de Mariana Masera Cerruti. 1976.

Entrevista con Mariana Masera realizada por Silvana Casal el 9 de noviembre de 2012 en Morelia, Michoacán. Llegó a México a los once años. Actualmente reside en Morelia, Michoacán, México.

Entrevista con Omar Masera, realizada por Silvana Casal el 25 de abril de 2012 en Morelia, Michoacán. Llegó a México a los 17 años. Actualmente reside en Morelia, Michoacán, México

\section{Páginas Web}

http://www.faqs.org/childhood/Ar-Bo/Autobiographies.html http://www.desaparecidos.org/nuncamas/web/investig/articulo/nuncamas/nmas1i01.htm 